\title{
Bioinformatic analysis of microRNA expression in Parkinson's disease
}

\author{
BIN HAO*, XIN CHEN*, DONGWEI DAI, CHAO ZOU, XI WU and JIANCHUN CHEN \\ Department of Neurosurgery, Changhai Hospital, Second Military Medical University, Shanghai 200433, P.R. China
}

Received January 19, 2014; Accepted October 1, 2014

DOI: $10.3892 / \mathrm{mmr} .2014 .2837$

\begin{abstract}
Parkinson's disease (PD) is a type of movement disorder caused by loss of dopamine-producing neurons in the midbrain. In order to identify the synergistic microRNA (miRNA) pattern in PD, miRNA and mRNA double expression profiles of PD were downloaded. Differentially expressed miRNA and mRNA were identified $[\mathrm{P}<0.01$, following false discovery rate (FDR) correction]. A cumulative hypergeometric distribution test was then performed to identify synergistic miRNAs $(\mathrm{P}<0.01$, following FDR correction). Gene ontology (GO) function and Kyoto Encyclopedia of Genes and Genomes (KEGG) pathway annotations were performed to analyze the miRNA regulatory target genes. Subsequently, a synergistic miRNA network was constructed and miRNAs exhibiting a high degree were identified. In total, 200 differentially expressed miRNA and 2,966 differentially expressed mRNA were identified. In addition, 1,502 synergistic miRNA interactions were identified, and miRNAs regulated 304 target genes in total. The GO and KEGG analysis demonstrated that these target genes were enriched in biosynthetic and cellular biosynthetic processes, the assembly of cellular components in morphogenesis, mitogen-activated protein kinase signaling, myometrial relaxation and contraction pathways as well as calcium regulation. The miRNA network demonstrated that miR-627, miR-634, miR-514, miR-563 and miR-613 had a high degree. miRNA with a high degree may be associated with the pathogenesis of PD and, therefore, may assist in the diagnosis and therapy of PD.
\end{abstract}

Correspondence to: Dr Xi Wu or Dr Jianchun Chen, Department of Neurosurgery, Changhai Hospital, Second Military Medical University, 168 Changhai Road, Yangpu, Shanghai 200433, P.R. China

E-mail: xiwuxiw@hotmail.com

E-mail: jianchunchenjc@hotmail.com

*Contributed equally

Key words: Parkinson's disease, differential expression analysis, synergistic miRNA network, function annotation

\section{Introduction}

Parkinson's disease (PD) is a disease of the nervous system, characterized by the loss of nigrostriatal dopaminergic neurons (NDN) (1). PD, also termed tremors paralysis, is a common age-associated neurodegenerative disease, which is associated with environmental and genetic factors $(2,3)$, with a prevalence of $0.3 \%$ in the whole population and an increasing incidence in the elderly (4). The main clinical manifestation of PD includes motionless tremor, which is limited to one side of the body. Clinically, PD features motionless tremor, muscle rigidity, bradykinesia and postural instability (5). At present, the therapeutic methods used for the treatment of PD involve pharmacotherapy, gene therapy, rehabilitation and surgical treatment. In 1967, clinical studies demonstrated that oral levodopa can improve the symptoms of PD, establishing its current status in the treatment of PD. Levodopa remains the most effective drug in PD therapy (6). However, treatment with levodopa is associated with various side-effects, including a decline in efficacy following prolonged usage, switch effect and end-of-dose phenomenon (7). Based on current understanding of the neural circuits of the basal ganglia (8), PD therapy predominantly requires the use of a dopamine D1 receptor-stimulating agent (9).

microRNAs (miRNA) are small, endogenous, RNA-coding molecules, which are important in almost all biological pathways, particularly in the transcriptional regulation of gene expression. As a small molecule regulator of gene transcription and expression, miRNAs are involved in almost all important biological pathways and disease processes in the human body (10). In recent years, there have been an increasing number of studies regarding the association of miRNAs with various diseases and biological functions. miRNAs are important in cancer, inflammation and infection as well as cardiovascular, immune and degenerative diseases acting as molecular markers for screening, but also may be used as new targets for drug development and the prevention and control of severe diseases (11).

Small, gene regulating miRNAs may also be important in PD. It has previously been reported that miRNA regulates leucine repeat kinase-2 (LRRK2) which contributes to the etiology of sporadic PD (12). Jewish individuals of European and North African descent often carry a LRRK2 mutation. These mutations are strongly associated with the occurrence of $\mathrm{PD}$, however, the specific mechanism remains to be elucidated. 
Based on data from miRNA and mRNA double expression profiles, the present study identified a synergistic miRNA pattern in PD and constructed an miRNA network. Through gene ontology (GO) function and Kyoto Encyclopedia of Genes and Genomes (KEGG) pathway annotation, the miRNA-associated pathogenesis of PD was determined. The changes in gene expression observed under pathological conditions assists in improving understanding of the pathogenesis of PD and facilitates the identification of corresponding targets for therapy. Gene expression profile analysis is a fast, high through-put detection method for miRNA expression in tissues or cells. Comparison of the differences in expression between patients and healthy controls using this method, improves knowledge of the pathogenesis and development of PD.

\section{Materials and methods}

miRNA and $m R N A$ expression profiles of $P D$. The miRNA and mRNA expression profiles of PD were downloaded from the Gene Expression Omnibus and were termed GSE16658 (http://www.ncbi.nlm.nih.gov/geo/query/ acc.cgi?acc=GSE16658; accessed 9th June 2013) and GSE22491 (http://www.ncbi.nlm.nih.gov/geo/query/acc. cgi?acc=GSE22491; accessed 9th June 2013), respectively $(13,14)$. miRNA expression profiling was performed using the miRCURY LNA microRNA Array platform, which included 32 samples (19 PD samples and 13 normal control samples). The mRNA profiling was performed using the Agilent-014850 Whole Human Genome Microarray 4x44K (G4112F) platform (Agilent Technologies, Inc., Santa Clara, CA, USA), which included 18 samples (10 PD samples and eight normal control samples).

Differential expression analysis for miRNA and $m R N A$ expression profiling. Probes of miRNA and mRNA profiling were mapped to the miRNA name and Entrez Gene ID in the miRBase, respectively. When multiple probes were mapped to one miRNA or gene, the average expression level was calculated. $\log 2$ conversion was then performed on the expression level.

A two-tailed student's t-test was used to analyze the differentially expressed miRNA and mRNA in the PD samples compared with the normal samples when the P-value was $<0.01$ following false discovery rate (FDR) adjustment.

Predicted target genes of miRNA and function and pathway enrichment analysis. Based on the seven target gene prediction algorithms PicTar, DIANA-microT, miRanda, miRBase, RNAhybrid, RNA22 and TargetScan, a set of predicted target genes of miRNA was determined. In order to reduce false positive predictions, miRNA target genes with high confidence were selected, which were predicted by at least three prediction algorithms. The miRNA target genes set with high confidence were then used for further analysis.

In order to determine which biological functions the synergistic miRNA was involved in, GO (15) was used for the miRNA regulatory target gene enrichment analysis $(\mathrm{P}<0.001)$. In addition, GenMAPP software (Gladstone Institute, San Francisco, CA, USA) (16) was used for KEGG pathway analysis.
Identification of synergistic miRNAs. Each miRNA set with high confidence of target genes was obtained and an accumulative hyper-geometric distribution test was performed to locate miRNAs sharing the same target genes. These miRNAs were defined as synergistic miRNAs. $\mathrm{P}<0.01$ was considered to indicate a statistically significant difference following multiple FDR adjustment.

\section{Results}

Differential expression analysis. For expression analysis, 200 significantly differentially expressed miRNAs were identified in the PD samples compared with the normal samples. In the mRNA expression profile analysis, 2,966 differentially expressed mRNAs were identified.

Identification of synergistic miRNA and functional annotation for target genes. A total of 3,860 abnormal miRNA interactions were identified, which regulated at least one common target gene. A total of 1,502 miRNA interactions $(\mathrm{P} \leq 0.01)$ were identified based on super geometric distribution algorithm, including 147 miRNAs. These significantly synergistic miRNA pairs were involved in the regulation of 304 abnormally expressed genes.

In order to determine the biological functions that PD-associated disordered miRNAs were involved in, 304 abnormal target genes were used to perform GO function enrichment. A total of $74 \mathrm{GO}$ biological processes were significantly enriched, including the biosynthetic process, the cellular biosynthetic process, the cellular component assembly involved in morphogenesis, mitogen-activated protein kinase (MAPK) signaling, the myometrial relaxation and contraction pathways and calcium regulation in the cardiac cell (Table I). In addition, 304 target genes were significantly enriched in eight KEGG pathways (Table II).

Synergistic miRNA network construction. The synergistic miRNA was used to construct a synergistic miRNA network associated with PD (Fig. 1). The miRNAs in this network comprised all the abnormal molecules in the disease process and are important gene regulatory factors. Therefore, the miRNAs in the network may be beneficial to uncover the mechanism of PD. Through binding to their target genes, miRNAs control post-transcriptional translation or directly degrade the mRNA target genes. Degree represents the number of interaction partners and the node with the highest degree is essential for the stabilization of the network (17). As shown in Table III, a high degree was observed in miR-627, miR-634, miR-514, miR-563 and miR-613, which may be associated with the pathogenesis of PD.

\section{Discussion}

PD is a common neurological degenerative disease in elderly individuals. It is well established that miRNA is involved in adjusting the target genes involved in cell proliferation, differentiation, apoptosis and extensive biological processes (18). In addition, miRNA is also important in the differentiation of stem cells $(19,20)$. Dysfunction of miRNA may affect the development of the nervous system, which causes diseases, including Alzheimer's disease and PD (21). In the present 
Table I. GO functional annotation of synergistic microRNA regulatory target genes.

\begin{tabular}{|c|c|c|}
\hline GO ID (Biological process) & P-value & Term \\
\hline GO:0009058 & $1.63 \mathrm{E}-04$ & Biosynthetic process \\
\hline GO:0044249 & $1.01 \mathrm{E}-04$ & Cellular biosynthetic process \\
\hline GO:0010927 & $2.72 \mathrm{E}-04$ & Cellular component assembly involved in morphogenesis \\
\hline GO:0034641 & $1.27 \mathrm{E}-04$ & Cellular nitrogen compound metabolic process \\
\hline GO:0016265 & $6.60 \mathrm{E}-05$ & Cell death \\
\hline GO:0006310 & $8.80 \mathrm{E}-04$ & DNA recombination \\
\hline GO:0033036 & $9.14 \mathrm{E}-06$ & Macromolecule localization \\
\hline GO:0043412 & $3.23 \mathrm{E}-05$ & Macromolecule modification \\
\hline GO:0008152 & $2.26 \mathrm{E}-04$ & Metabolic process \\
\hline GO:0048519 & $5.61 \mathrm{E}-05$ & Negative regulation of biological process \\
\hline GO:0006807 & $1.94 \mathrm{E}-04$ & Nitrogen compound metabolic process \\
\hline GO:0008104 & 4.20E-06 & Protein localization \\
\hline GO:0015031 & $1.48 \mathrm{E}-05$ & Protein transport \\
\hline GO:0050789 & $1.00 \mathrm{E}-04$ & Regulation of biological process \\
\hline GO:0010468 & $2.26 \mathrm{E}-06$ & Regulation of gene expression \\
\hline GO:0019219 & $1.07 \mathrm{E}-05$ & Regulation of nucleobase-containing compound metabolic process \\
\hline GO:0080090 & $1.63 \mathrm{E}-06$ & Regulation of primary metabolic process \\
\hline GO:0051252 & $6.76 \mathrm{E}-06$ & Regulation of RNA metabolic process \\
\hline GO:0044281 & $3.21 \mathrm{E}-04$ & Small molecule metabolic process \\
\hline GO:0006915 & $3.52 \mathrm{E}-04$ & Apoptosis \\
\hline GO:0065007 & $1.47 \mathrm{E}-04$ & Biological regulation \\
\hline GO:0008219 & $6.39 \mathrm{E}-05$ & Cell death \\
\hline GO:0051641 & $7.15 \mathrm{E}-07$ & Cellular localization \\
\hline GO:0034645 & $3.39 \mathrm{E}-06$ & Cellular macromolecule biosynthetic process \\
\hline GO:0044265 & $2.60 \mathrm{E}-04$ & Cellular macromolecule catabolic process \\
\hline GO:0070727 & $3.98 \mathrm{E}-07$ & Cellular macromolecule localization \\
\hline GO:0044260 & $1.69 \mathrm{E}-08$ & Cellular macromolecule metabolic process \\
\hline GO:0044237 & $5.70 \mathrm{E}-07$ & Cellular metabolic process \\
\hline GO:0009987 & $2.29 \mathrm{E}-05$ & Cellular process \\
\hline GO:0044257 & 7.03E-04 & Cellular protein catabolic process \\
\hline GO:0034613 & $1.06 \mathrm{E}-06$ & Cellular protein localization \\
\hline GO:0044267 & $6.43 \mathrm{E}-05$ & Cellular protein metabolic process \\
\hline GO:0033554 & $9.44 \mathrm{E}-04$ & Cellular response to stress \\
\hline GO:0051649 & $3.09 \mathrm{E}-05$ & Establishment of localization in cell \\
\hline GO:0045184 & $5.25 \mathrm{E}-06$ & Establishment of protein localization \\
\hline GO:0010467 & $3.81 \mathrm{E}-05$ & Gene expression \\
\hline GO:0006886 & $1.58 \mathrm{E}-05$ & Intracellular protein transport \\
\hline GO:0046907 & $3.68 \mathrm{E}-08$ & Intracellular transport \\
\hline GO:0009059 & $8.70 \mathrm{E}-06$ & Macromolecule biosynthetic process \\
\hline GO:0043170 & $6.81 \mathrm{E}-06$ & Macromolecule metabolic process \\
\hline GO:0043632 & $3.94 \mathrm{E}-04$ & Modification-dependent macromolecule catabolic process \\
\hline GO:0019941 & $3.58 \mathrm{E}-04$ & Modification-dependent protein catabolic process \\
\hline GO:0016071 & $1.53 \mathrm{E}-04$ & mRNA metabolic process \\
\hline GO:0006397 & $1.12 \mathrm{E}-05$ & mRNA processing \\
\hline GO:0048523 & $2.05 \mathrm{E}-05$ & Negative regulation of cellular process \\
\hline GO:0090304 & $3.62 \mathrm{E}-06$ & Nucleic acid metabolic process \\
\hline GO:0006139 & $2.71 \mathrm{E}-05$ & Nucleobase-containing compound metabolic process \\
\hline GO:0006996 & 3.93E-04 & Organelle organization \\
\hline GO:0006596 & $6.75 \mathrm{E}-04$ & Polyamine biosynthetic process \\
\hline GO:0051574 & $3.38 \mathrm{E}-04$ & Positive regulation of histone $\mathrm{H} 3-\mathrm{K} 9$ methylation \\
\hline GO:0044238 & $2.02 \mathrm{E}-05$ & Primary metabolic process \\
\hline
\end{tabular}


Table I. Table I. Continued.

\begin{tabular}{|c|c|c|}
\hline GO ID (Biological process) & P-value & Term \\
\hline GO:0012501 & $2.14 \mathrm{E}-04$ & Programmed cell death \\
\hline GO:0071539 & $3.38 \mathrm{E}-04$ & Protein localization to centrosome \\
\hline GO:0033365 & $6.95 \mathrm{E}-04$ & Protein localization to organelle \\
\hline GO:0032446 & $7.82 \mathrm{E}-05$ & Protein modification by small protein conjugation \\
\hline GO:0070647 & $1.93 \mathrm{E}-04$ & Protein modification by small protein conjugation/removal \\
\hline GO:0006464 & $7.95 \mathrm{E}-06$ & Protein modification process \\
\hline GO:0016567 & $3.19 \mathrm{E}-04$ & Protein ubiquitination \\
\hline GO:0051603 & $5.37 \mathrm{E}-04$ & Proteolysis involved in cellular protein catabolic process \\
\hline GO:0009889 & $3.13 \mathrm{E}-05$ & Regulation of biosynthetic process \\
\hline GO:0031326 & $2.24 \mathrm{E}-05$ & Regulation of cellular biosynthetic process \\
\hline GO:2000112 & $9.66 \mathrm{E}-07$ & Regulation of cellular macromolecule biosynthetic process \\
\hline GO:0031323 & $1.34 \mathrm{E}-06$ & Regulation of cellular metabolic process \\
\hline GO:0050794 & $2.66 \mathrm{E}-05$ & Regulation of cellular process \\
\hline GO:0010556 & $2.43 \mathrm{E}-06$ & Regulation of macromolecule biosynthetic process \\
\hline GO:0060255 & $5.68 \mathrm{E}-06$ & Regulation of macromolecule metabolic process \\
\hline GO:0019222 & $7.90 \mathrm{E}-06$ & Regulation of metabolic process \\
\hline GO:0051171 & $4.62 \mathrm{E}-06$ & Regulation of nitrogen compound metabolic process \\
\hline GO:0006355 & $1.54 \mathrm{E}-05$ & Regulation of transcription, DNA-dependent \\
\hline GO:0032774 & $7.31 \mathrm{E}-05$ & RNA biosynthetic process \\
\hline GO:0016070 & 8.94E-06 & RNA metabolic process \\
\hline GO:0008380 & $2.36 \mathrm{E}-05$ & RNA splicing \\
\hline GO:0006351 & 2.61E-05 & Transcription, DNA-dependent \\
\hline GO:0006511 & $2.85 \mathrm{E}-04$ & Ubiquitin-dependent protein catabolic process \\
\hline
\end{tabular}

GO, gene ontology.

Table II. Kyoto Encyclopedia of Genes and Genomes pathway annotation of synergistic microRNA regulatory targeted genes.

\begin{tabular}{llc}
\hline Pathway & \multicolumn{1}{c}{ MAPP name } & $\begin{array}{c}\text { Adjusted } \\
\text { P-value }\end{array}$ \\
\hline WP382 & $\begin{array}{l}\text { Mitogen-activated protein } \\
\text { kinase signaling }\end{array}$ & 0 \\
WP289 & $\begin{array}{l}\text { Myometrial relaxation and } \\
\text { contraction }\end{array}$ & 0 \\
WP536 & Calcium regulation in the & \\
WP481 & cardiac cell & 0 \\
WP23 & Insulin signaling & \\
WP254 & Apoptosis receptor signaling & 0 \\
WP707 & DNA damage response & 0 \\
WP1591 & Heart development & 0 \\
& & 0 \\
\hline
\end{tabular}

study, the expression profiles of miRNA and mRNA were used to identify disordered miRNA. A total of 304 abnormal miRNA regulatory target genes were identified. GO function and KEGG pathway analysis demonstrated that miRNA regulatory target genes were enriched in several biosynthetic processes and pathways, among which cell apoptosis $(22,23)$,
Table III. Degree of miRNA in the PD-associated network.

\begin{tabular}{lc}
\hline miRNA & Degree \\
\hline miR-627 & 58 \\
miR-634 & 50 \\
miR-514 & 48 \\
miR-563 & 48 \\
miR-613 & 46 \\
miR-106a & 46 \\
miR-383 & 44 \\
miR-557 & 44 \\
miR-505 & 459
\end{tabular}

miRNAs with the 10 highest degrees are presented. miRNA, microRNA.

the MAPK signal pathway (24), calcium ion regulation (25) and insulin signals (26) have been associated with the development or the treatment process and response to DNA damage in PD.

In the present study, a total of 1,502 synergistic miRNA interactions were identified and an miRNA synergistic network was constructed. Within this network, miR-7 has 


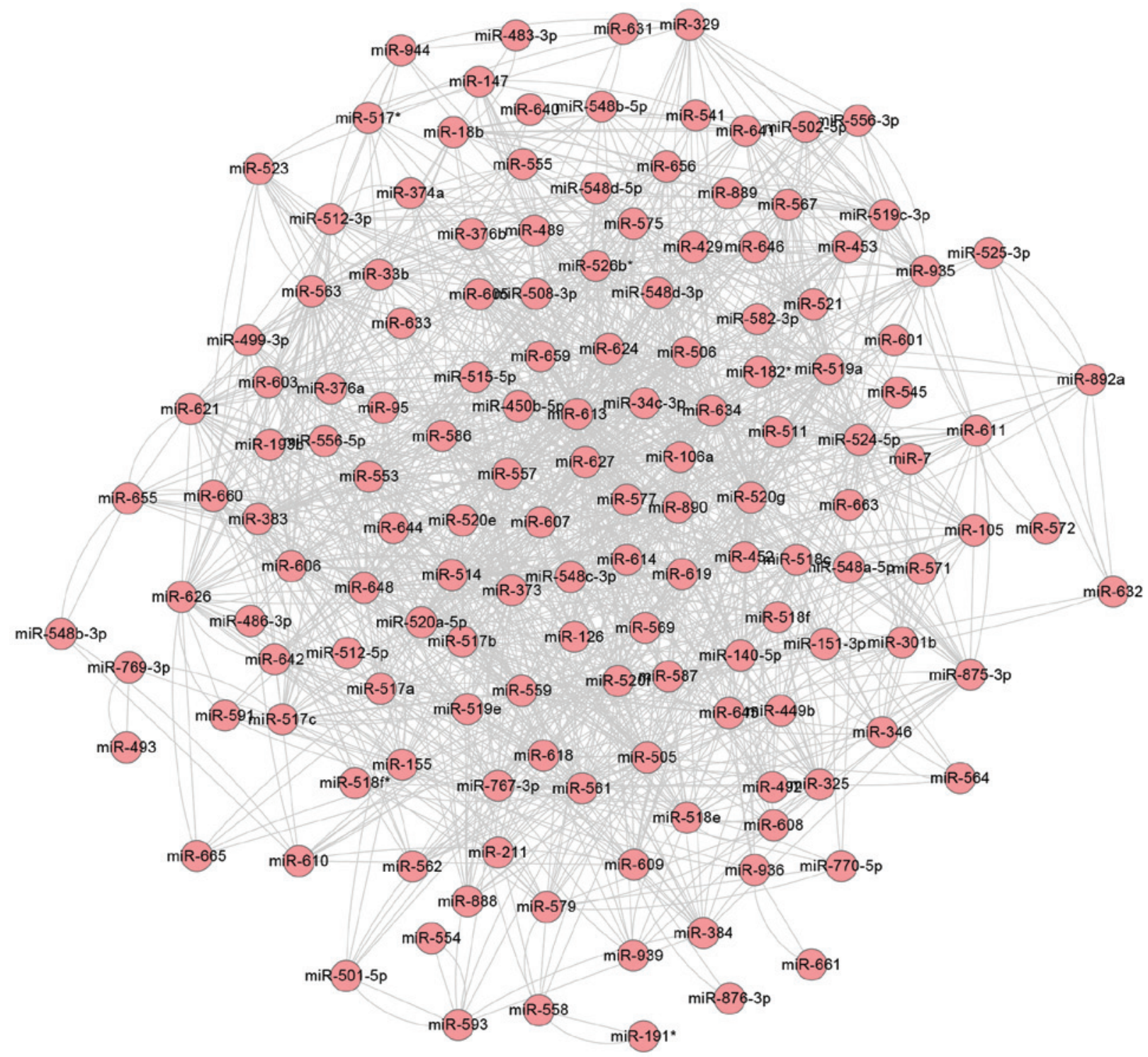

Figure 1. Synergistic miRNA network associated with Parkinson's disease. Nodes represent differentially expressed genes. miRNA, microRNA.

been demonstrated to regulate critical genes in the nervous system and to be involved the processes of PD (14,27). In the synergistic network constructed in the present study, miR-7 and another six miRNAs regulated common target genes. In addition, through binding to the 3'UTR of amyloid precursor protein (APP), miR-147 regulated the level of APP expression and, therefore, affected the risk of developing Alzheimer's disease and PD (28). The miRNA network demonstrated that miR-627, miR-634, miR-514, miR-563 and miR-613 exhibited a high degree. miR-627, miR-634 and miR-514 have been investigated in human colorectal cancer cells (29), acute lymphoblastic leukemia (30) and ovarian cancer (31). miR-563 has been reported to be differentially expressed in Alzheimer's disease samples (32) and targets the nuclear liver $\mathrm{X}$ receptor, which is important in the metabolism and homeostasis of cholesterol, bile acids, lipids and steroid hormones (33). However, to the best of our knowledge, no studies have investigated the association between these miRNAs and PD or other nerve-associated diseases. Therefore, the present study demonstrated for the first time, to the best of our knowledge, that miR-627, miR-634, miR-514, miR-563 and miR-613 are associated with PD. Further studies are required in order to confirm these results.

Using the expression profile data, the entire genomic expression situation of PD was examined. This revealed differentially expressed miRNAs and mRNAs. In addition, miRNAs were obtained and a synergistic miRNA network was constructed. From this, miR-627, miR-634, miR-514, miR-563 and miR-613 were obtained, which were newly reported in the present study. However, further studies are required to confirm these results.

\section{Acknowledgements}

This study was supported by grants from The Major Project of Biomedical Research of the Science and Technology Commission of Shanghai Municipality (grant no. 10411954400) and The National Natural Science Foundation of China General Program (grant no. 81171296). 


\section{References}

1. McCormack AL, Thiruchelvam M, Manning-Bog AB, et al: Environmental risk factors and Parkinson's disease: selective degeneration of nigral dopaminergic neurons caused by the herbicide paraquat. Neurobiol Dis 10: 119-127, 2002.

2. Findley L, Gresty M and Halmagyi G: Tremor, the cogwheel phenomenon and clonus in Parkinson's disease. J Neuro Neurosurg Psychiatry 44: 534-546, 1981.

3. Parsian A, Sinha R, Racette B, Zhao JH and Perlmutter JS: Association of a variation in the promoter region of the brain-derived neurotrophic factor gene with familial Parkinson's disease. Parkinsonism Relat Disord 10: 213-219, 2004.

4. de Lau LM and Breteler MM: Epidemiology of Parkinson's disease. Lancet Neurol 5: 525-535, 2006.

5. Rajput A, Rozdilsky B, Ang L and Rajput A: Significance of parkinsonian manifestations in essential tremor. Can J Neurol Sci 20: 114-117, 1993.

6. Jankovic J: Levodopa strengths and weaknesses. Neurology 58: S19-S32, 2002.

7. Zheng H, Fridkin M and Youdim MB: Site-activated chelators derived from anti-Parkinson drug rasagiline as a potential safer and more effective approach to the treatment of Alzheimer's disease. Neurochem Res 35: 2117-2123, 2010.

8. Hashimoto T: Functional models of movement disorders of basal ganglia origin and effects of functional neurosurgery. Rinsho Shinkeigaku 47: 21-26, 2007 (In Japanese).

9. Wagg A: The review article by Wood et al on nonmotor symptoms of Parkinson's disease (PD) in the August 2010 edition of The American Journal of Geriatric Pharmacotherapy. Am J Geriatr Pharmacother 9: 93-94, 2011.

10. Chen K and Rajewsky N: The evolution of gene regulation by transcription factors and microRNAs. Nat Rev Genet 8: 93-103, 2007.

11. Zhang C: Novel functions for small RNA molecules. Curr Opin Mol Ther 11: 641-651, 2009.

12. Gehrke S, Imai Y, Sokol N and Lu B: Pathogenic LRRK2 negatively regulates microRNA-mediated translational repression. Nature 466: 637-641, 2010.

13. Mutez E, Larvor L, Lepretre F, et al: Transcriptional profile of Parkinson blood mononuclear cells with LRRK2 mutation. Neurobiol Aging 32: 1839-1848, 2011.

14. Martins M, Rosa A, Guedes LC, et al: Convergence of miRNA expression profiling, $\alpha$-synuclein interacton and GWAS in Parkinson's disease. PloS One 6: e25443, 2011.

15. Ashburner M, Ball CA, Blake JA, et al: Gene ontology: tool for the unification of biology. The Gene Ontology Consortium. Nat Genet 25: 25-29, 2000.

16. Dahlquist KD, Salomonis N, Vranizan K, Lawlor SC and Conklin BR: GenMAPP, a new tool for viewing and analyzing microarray data on biological pathways. Nat Genet 31: 19-20,2002.

17. Xu J, Li CX, Li YS, et al: MiRNA-miRNA synergistic network: construction via co-regulating functional modules and disease miRNA topological features. Nucleic Acids Res 39: 825-836, 2011
18. Chen Y and Stallings RL: Differential patterns of microRNA expression in neuroblastoma are correlated with prognosis, differentiation, and apoptosis. Cancer Res 67: 976-983, 2007.

19. Marson A, Levine SS, Cole MF, et al: Connecting microRNA genes to the core transcriptional regulatory circuitry of embryonic stem cells. Cell 134: 521-533, 2008.

20. Murchison EP, Partridge JF, Tam OH, Cheloufi S and Hannon GJ: Characterization of Dicer-deficient murine embryonic stem cells. Proc Natl Acad Sci USA 102: 12135-12140, 2005.

21. Hébert SS and De Strooper B: Molecular biology. miRNAs in neurodegeneration. Science 317: 1179-1180, 2007.

22. Anglade P, Vyas S, Javoy-Agid F, et al: Apoptosis and autophagy in nigral neurons of patients with Parkinson's disease. Histol Histopathol 12: 25-31, 1997.

23. Tatton WG, Chalmers-Redman R, Brown D and Tatton N: Apoptosis in Parkinson's disease: signals for neuronal degradation. Ann Neurol 53: S61-S70; discussion S70-S72, 2003

24. Yogev-Falach M, Amit T, Bar-Am O and Youdim MB: The importance of propargylamine moiety in the anti-Parkinson drug rasagiline and its derivatives in MAPK-dependent amyloid precursor protein processing. FASEB J 17: 2325-2327, 2003.

25. Sheehan JP, Swerdlow RH, Parker WD, Miller SW, Davis RE and Tuttle JB: Altered calcium homeostasis in cells transformed by mitochondria from individuals with Parkinson's disease. J Neurochem 68: 1221-1233, 1997.

26. Bruning JC, Gautam D, Burks DJ, et al: Role of brain insulin receptor in control of body weight and reproduction. Science 289: 2122-2125, 2000.

27. Fiore R, Siegel G and Schratt G: MicroRNA function in neuronal development, plasticity and disease. Biochim Biophys Acta 1779: 471-478, 2008

28. Delay C, Calon F, Mathews P and Hébert SS: Alzheimer-specific variants in the 3'UTR of Amyloid precursor protein affect microRNA function. Mol Neurodegener 6: 70, 2011.

29. Padi SK, Zhang Q, Rustum YM, Morrison C and Guo B: MicroRNA-627 mediates the epigenetic mechanisms of vitamin D to suppress proliferation of human colorectal cancer cells and growth of xenograft tumors in mice. Gastroenterology 145: 437-446, 2013.

30. Rainer J, Ploner C, Jesacher S, et al: Glucocorticoid-regulated microRNAs and mirtrons in acute lymphoblastic leukemia. Leukemia 23: 746-752, 2009.

31. Boren T, Xiong Y, Hakam A, et al: MicroRNAs and their target messenger RNAs associated with ovarian cancer response to chemotherapy. Gynecol Oncol 113: 249-255, 2009.

32. Kumar P, Dezso Z, MacKenzie C, et al: Circulating miRNA biomarkers for Alzheimer's disease. PloS One 8: e69807, 2013.

33. Ou Z, Wada T, Gramignoli R, et al: MicroRNA hsa-miR-613 targets the human LXR $\alpha$ gene and mediates a feedback loop of LXR $\alpha$ autoregulation. Mol Endocrinol 25: 584-596, 2011. 